\title{
Quality of commitment: Japanese daroo as a speech act operator
}

\author{
Lukas Rieser \\ KYOTO UNIVERSITY \\ lukasjrieser@gmail.com
}

\begin{abstract}
This paper proposes a compositional analysis of the meaning of Japanese daroo-utterances with declarative and interrogative force, and final rising and falling intonation. Daroo is analyzed in a framework for speech act felicity as an operator lowering the quality threshold for felicitous assertion. The conveyed meanings of conjecture, confirmation, and doubt uses of darooutterances are predicted from modification of the respective speech act types' felicity conditions by daroo. ${ }^{1}$
\end{abstract}

\section{Preliminaries}

Speech act felicity has been widely discussed at least since Austin (1962) introduced the concepts of illocutionary act and illocutionary force. Building on Searle (1969) and Grice (1975), I provide a framework to formalize speech act felicity conditions and how daroo modifies them. In addition to declarative and interrogative force, I distinguish final falling and rising intonation, modeling four types of speech acts: falling declaratives (FDs) or canonical assertions, falling interrogatives (FIs), rising declaratives (RDs), and rising interrogatives (RIs) or canonical questions and derive their felicity conditions compositionally.

The framework represents what a speech act "does" to the context (in form of commitments and forgone commitments arising from declaratives and interrogatives), and what needs to be the case in order for the speech act to do so (in form of belief and evidence conditions required to hold for the speech act to be performed felicitously). On this view, utterance meaning is a combination of the propositional level - the propositional content, or prejacent, that is "said" (in declaratives) or "doubted" (in interrogatives), and the speech act level - what the effect the act of saying

\footnotetext{
1 The framework for speech act felicity and the basic semantics of daroo build on Rieser (2017a), which focuses on the particle no. In this paper, doubt and confirmation uses of daroo as well as well as connections to other analyses are discussed in more detail .
} 


\section{Lukas Rieser: Quality of commitment}

or doubting has, and what it requires to be performed. It is on the speechact level of utterance meaning that I assume daroo modifies utterance meaning, accounting for its effect in combination with the interrogative particle $k a$ and the evidence particle no, both speech act operators as well.

The paper is structured as follows. Section 2 introduces the uses of daroo to be accounted for. Section 3 discusses extant generalizations and analyses. Section 4 introduces the framework for speech act felicity, and section 5 puts forward the analysis of daroo in this framework. Section 6 provides a summary of the analysis and an outlook on future research.

\section{Uses of daroo}

In this section, I discuss three uses of daroo-utterances I label conjecture, doubt, and confirmation. Conjecture is the use of daroo that formal analyses have focused on and is limited to FDs (assertions). It conveys speaker bias towards the prejacent in two flavors: a guess reading and an evidence-based inference reading, the latter connecting daroo to evidential expressions in Japanese. Next, doubt is a use limited to FIs (falling interrogatives), which do not convey speaker bias, but that the speaker is either wondering about or doubting the truth of the prejacent. Finally, the confirmation use is limited to declaratives, and is the only use of daroo that can occur with final rising intonation. It conveys not only speaker bias, but that the speaker believes the prejacent to be true, and seeks to confirm whether the addressee shares this belief. The analysis seeks to account for all uses with a single semantics for daroo.

\subsection{Conjecture}

On its conjecture use, daroo marks the prejacent of an assertion to be either a general assumption (or guess) of the speaker, or the result of evidence-based inference. Example (1), originally proposed by Morimoto (1994), illustrates Takubo's (2009) observation that the particle no is mandatory for the evidence-based inference reading, and that daroo shares this reading with the (indirect) evidential marker yooda.

(1) Kanojo-wa moo kekkon-shita \{(no) daroo / yooda $\}$. She-TOP already married-got no daroo yooda

"She got married already, $\{$ I bet / it seems $\}$ ".

The scenarios in (2) bring out the two readings of daroo in conjecture use.

(2) a. $\mathrm{S}$ is wondering about a former girlfriend years later.

b. $\mathrm{S}$ is wondering about a former girlfriend years later and notices her name changed on the alumni newsletter.

(2-a) brings out the guess reading, as there is no concrete evidence to support the assumption that she has got married. (2-b) brings out the evidence-based inference reading, on which the speaker is inferring that the ex-girlfriend likely got married from the premise that her name has changed as the evidence in the utterance situation shows. The acceptability 
of (1) in these scenarios depends on the presence or absence of no, and patterns with yooda 'seem' when no is added, as shown in (3).2

(3) a. no evidence

b. evidence-based conjecture

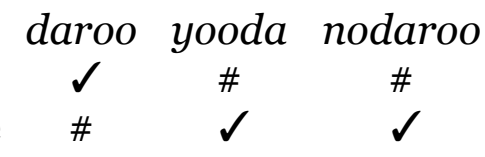

Both variants of the daroo-assertion in (1) convey speaker bias, i.e. that the speaker is considering the prejacent to be more likely than its negation. With no is added, the utterance further conveys that this bias is the result of evidence-based inference. Note that neither scenario allows bare assertion, as there is no direct evidence for the truth of the prejacent. ${ }^{\text {It }}$ should be noted that yooda shares the evidence-based inference use with daroo, but occurs neither in confirmations nor in expressions of doubt.

\subsection{Doubt}

(4) shows a variant of the conjecture example in (1) with the interrogative particle $k a$ added. Note that this makes final rising intonation unavailable. The English paraphrase "I wonder..." illustrates an interpretation as a potentially self-addressed question, or expression of doubt, rather than an addressee-oriented, information-seeking question. Addition of "really" approximates the effect of adding no, bringing out a reading on which the speaker doubts the validity of an inference that she got married.

(4) Kanojo-wa moo kekkon-shita(no) daroo ka $\{\triangleleft / \# \nearrow\}$ She-TOP already married-got no daroo INT

„I wonder if she (really) got married already.”

Thus, this example is not information-seeking in the way that canonical questions (RIs) typically are, which is typical for FIs. In contrast to daroodeclaratives, it does not convey speaker bias towards the prejacent, and, especially when no is added, can convey speaker bias against the prejacent. This is a marked contrast to bare falling interrogatives, as the one shown in (5) below, where adding no makes a belief-revision reading salient.

(5) Kanojo-wa moo kekkon-shita (no) ka ১

She-TOP already married-got no INT

„Did she get married already!”

This example has a doubt reading similar to the daroo-FI, but also readings indicating belief revision on part of the speaker. The bare variant has a reading on which it conveys (mild) speaker surprise over the (observed) truth of the prejacent, the variant with no a reading conveying

\footnotetext{
${ }^{2}$ Scenarios where evidence is strong enough to support the inference, but weak enough to disallow bare assertion can be difficult to construct, as the perceived strength of evidence varies by speaker. Nevertheless, contrasts observable in minimal pairs are fairly robust.

3 Versions with epistemic modals, such as kamoshirenai 'might' or nichigainai 'must', would also be licit, but these operate on the propositional, rather than on the speech-act level of meaning. Due to space, I cannot discuss these expressions here.
} 


\section{Lukas Rieser: Quality of commitment}

that the speaker has revised a previous expectation against the prejacent's truth, based on the available evidence. 4

The variant with daroo in (4), on the other hand, cannot convey that the speaker has revised a previous belief based on evidence, but only that the speaker (still) doubts the truth of the prejacent. That is, falling daroointerrogatives convey stronger doubt than bare falling interrogatives, particularly when no is added. Daroo-assertions on their conjecture use, on the other hand, convey weaker commitment than their bare counterparts. These are observations to be accounted for in the analysis.

\subsection{Confirmation}

(6) shows two variants of the conjecture example in (1), one with final falling and one with final rising intonation, to illustrate the confirmation uses of daroo. The English paraphrases, a final falling tag "isn't she" and a final rising tag “...right?”, reflect that the final falling variant is typically used in a turn-holding move, while the final rising variant typically requires a reaction from the addressee. Note the rising variant is given with the polite form deshoo, with a shortened variant desho which is limited to final rising environments.

(6) Kanojo-wa kekkon-shiteiru $\{$ daroo $\searrow / \operatorname{desho(o)~} \nearrow$ \} She-TOP married-be daroo daroo

"She's married, \{isn't she. / right? \}".

Crucially, neither confirmation variant conveys that the speaker is biased towards or doubts the prejacent. Rather, the falling version confirms whether the prejacent is indeed accepted by both speaker and addressee, i.e. part of a common ground in the sense of mutually accepted propositions, while the rising version checks whether the speaker's assumption that the addressee (also) believes the prejacent to be true is correct. Thus, daroo-declaratives in confirmation use convey that the speaker believes the prejacent to be true, but is not certain whether or not the addressee shares this belief. This use of daroo-utterances is difficult to capture on analyses taking daroo to be either an evidential or an inferential marker.

\section{Previous analyses}

While there is a wealth of descriptive work, mainly in Japanese, on darooutterances in their various uses, there exist few formal analyses. Below, I selectively summarize some generalizations and extant formal analyses before moving on to my analysis of daroo.

\subsection{Moriyama (1992)}

Building on previous work analyzing daroo as a marker of speaker judgment, Moriyama takes daroo to indicate that a "judgment-forming

4 Davis (2011) discusses this reading in detail, motivating an analysis of no as an evidential marker. In Rieser (2017a), I label this the „incredulity” reading. 
process" is underway, i.e. a belief w.r.t. the prejacent is in the process of formation, and daroo-interrogatives 5 to indicate the speaker does not expect to reach such a judgment. Moriyama differentiates two kinds of confirmations, namely "inquiring" and "pushing" varieties. The former indicate that a shared belief is in the process of formation, and are used to inquire about the addressee's belief. In the latter, there is a discrepancy between speaker and addressee belief, and the speaker seeks to convince the addressee of the prejacent's truth to form a shared belief. With regard to intonation, Moriyama notes that confirmations come with either a "sudden final fall"6 or final rise.

\subsection{Hara (2006)}

Hara proposes an analysis of daroo as a modal that restricts the modal base to the „possible worlds which are compatible with the speaker's nonobservable reasoning", that is daroo lexically encodes the restriction to not evidence-based conjecture with a quantificational force of „more than 50\%". My account is similar in that I take the required subjective likelihood of the prejacent, and thus the quantificational force of daroo, to be more than 50\%. However, I take quantification to occur over all doxastically accessible worlds and daroo to be a speech-act level operator, which is closer in spirit to Hara and Davis (2013), summarized below.

\subsection{Takubo (2009)}

Takubo seeks to explain his observation that no makes daroo-assertions felicitous in scenarios with evidence by analyzing daroo as an epistemic modal marking deductive inference, which no allows to mark abductive inference by scope-widening. This means that daroo marks modus ponens inference by which a conditional consequent is judged true on the premise that the antecedent holds, and that adding no allows inference in the other direction, namely that a conditional antecedent is true on the premise that the consequent holds. Applied to (1), this means that no-daroo indicates the speaker is inferring from the premises that the name changed and that when women get married, they usually change their names that her having married is a likely explanation for her name having changed. While this analysis accounts for the facts on daroo-conjectures, there does not seem to be a straightforward way of applying it to confirmations.

\subsection{Hara and Davis (2013)}

Hara and Davis propose that speaker bias in daroo-assertions is a result of update on speaker belief rather than on mutually accepted propositions. Following Groenendijk and Roelofsen (2009), they model a context set from pairs of equivalent worlds. Declarative update eliminates pairs containing worlds at which the prejacent is false, while inquisitive update

5 Moriyama discusses daroo utterances with $w h$-expressions as examples for interrogatives rather than daroo-ka utterances as discussed in this paper.

6 In such cases, the final vowel can be shortened to yield “. . . darol” 


\section{Lukas Rieser: Quality of commitment}

partitions the context to contain pairs where the prejacent is true at one world, false at the other. Daroo modifies the modal base so that update targets doxastically accessible worlds, i.e. worlds that are compatible with the speaker's beliefs.

H\&D assume that final rising intonation shifts the "deictic center" of daroo (the agent of updated beliefs) to the addressee and hypothesize that when the overt force marker $k a$ intervenes between the final rise and daroo, this shifting is blocked. This explains the marginal status of rising daroo- $k a$ utterances thus predicted to convey "do you know whether I believe [the prejacent]", a meaning only compatible with quiz questions.7

The infelicity of bare daroo-conjecture with evidence is explained by lexical specification of different types of evidence within Davis et al.'s (2007) context-shifting semantics, where a contextual parameter $\mathrm{C} \tau$ determines the subjective probability required for felicitous assertion, reflecting the first Gricean maxim of quality. H\&D argue that yooda requires 'indirect' evidence, while daroo accepts 'all evidence', and that utterance felicity depends on evidence of the required type and on subjective probability clearing the corresponding threshold C $\tau$. Thus, daroo and yooda indirectly change the required subjective probability $\mathrm{C} \tau$ by lowering the threshold in a process labeled "context shifting". Hara and Davis leave the effect of no assimilating daroo to yooda as an open issue, mentioning the possibility of analyzing no as a question particle.

\section{A framework for speech-act felicity}

In this section, I formalize the felicity conditions of the aforementioned four speech act types in terms of belief and evidence, building on Gricean conversational maxims and the Searlean preparatory condition on interrogatives. I compositionally derive each type's felicity conditions from illocutionary force and sentence-final intonation. I first show how speaker commitment arises from satisfaction of the belief and evidence conditions on declaratives. Moving on to interrogatives, which do not make but forgo commitments, I show that they give rise to implicatures derived as negation of the respective declarative alternative's commitment. Finally, I show sentence-final intonation to resolve the target of commitment to the speaker (final fall) or the addressee (final rise).

\subsection{Gricean Quality and commitment from assertion}

Grice (1975) formulates two specific maxims based on the supermaxim of quality for assertions "Try to make your contribution one that is true".

Quality I Do not say what you believe to be false.

Quality II Do not say that for which you lack adequate evidence.

\footnotetext{
7 Searle (1969) differentiates „exam questions” from „real questions”, as in the former the speaker knows the answer and wants to find out whether the addressee does, too, while in the latter the speaker does not know the answer. This is an interesting connection with potential implications for the current proposal, which for space I have to leave for further research.
} 
I take these maxims to be conditions on felicitous utterance of an assertion which require the world at utterance time to be such that the prejacent is compatible with the speaker's beliefs, and there is evidence available to the speaker which, considered in isolation, is sufficient to conclude that, i.e. support a belief that, the prejacent is true. ${ }^{8}$ These conditions are shown in (7) and (8) below (Bs $\varphi$ and $\mathrm{EV}_{\mathrm{S}} \varphi$ are to be defined shortly).

(7) Evidence condition on $\operatorname{DECs}(\varphi) \downarrow$ (Quality I): $\quad \operatorname{EV}_{S} \varphi$

(8) Belief condition on $\operatorname{DECs}(\varphi) \downarrow \quad$ (Quality II): $\neg \mathrm{B}_{s} \neg \varphi$

$\operatorname{DECs}(\varphi) \searrow$ represents a falling declarative utterance of agent $S$ (speaker) with prejacent $\varphi$, that is assertion of $\varphi$ by S. Note that I closely follow Grice's formulation of Quality II and do not assume a condition Bs $\varphi$, that is a requirement that the speaker believe the prejacent to be true. ${ }^{9}$

(9) and (10) show definitions of non-negated and negated belief in terms of doxastic states. Doxs denotes the set of worlds compatible with S's beliefs, i.e. the doxastic state of the speaker. ${ }^{10}$

$$
\begin{aligned}
& \text { Bs } \varphi \text { is true iff DoXs } \subseteq \mathrm{W}^{\varphi} \\
& \neg \mathrm{Bs} \varphi \text { is true iff DoXs } \nsubseteq \mathrm{W}^{\varphi} \\
& \quad \text { (where } \mathrm{W}^{\varphi} \text { denotes the set of worlds at which } \varphi \text { is true.) }{ }^{11}
\end{aligned}
$$

When an assertion is observed and assumed to be felicitous in that (7) and (8) are satisfied, it can be inferred that the speaker believes the prejacent to be true, all else being equal. The defeasible entailment ${ }^{12}$ relation in (11) accordingly defines the relation of belief and evidence, thus indirectly defining evidence by its relation to belief.

(11) a. $\operatorname{EVS} \varphi>\operatorname{Bs} \varphi$

b. $[(\operatorname{EVs} \varphi>\operatorname{Bs} \varphi) \wedge \operatorname{EVs} \varphi] \wedge \quad \operatorname{Bs} \neg \varphi \not t \operatorname{Bs} \varphi$

c. $\left[\left(\operatorname{EVS}_{S} \varphi>\operatorname{BS} \varphi\right) \wedge \operatorname{EV}_{S} \varphi\right] \wedge \neg \operatorname{BS} \neg \varphi \vdash \operatorname{BS} \varphi$

According to (11a), it can usually be inferred that $S$ believes $\varphi$ to be true when the evidence condition on $\operatorname{DECs}(\varphi) \downarrow$ is satisfied. (11b) states $B_{S} \neg \varphi$ as the blocking condition, i.e. the inference is defeated when the observer assumes the speaker to believe the prejacent to be false. (11c) shows that satisfaction of the belief condition on $\operatorname{DECs}(\varphi) \searrow$ ensures that the inference goes through, thus speaker commitment arises from assertion.

Since a speech act is a "manifest event" (Stalnaker 2002), I further assume commitment takes the form of a public belief $\operatorname{PBs} \varphi$, which holds when $\operatorname{BS}_{S} \varphi$ is inferred from $\operatorname{DECs}(\varphi) \searrow$, as in (12), and is defined in (13).

(12) Commitment from $\operatorname{DECs}(\varphi) \searrow: \operatorname{PB~} s \varphi$

(13) $\operatorname{PBS} \varphi \leftrightarrow B_{A} B_{S} \varphi \wedge B_{S} B_{A} B_{S} \varphi$

8 This builds on Büring and Gunlogson's (2000) definition of „compelling” evidence.

9 Against Searle (1969), who proposes such a sincerity condition for assertions.

10 For simplicity, I gloss over the potential necessity of restricting these worlds by an additional conversational background such as a stereotypical ordering source (Kratzer 1981).

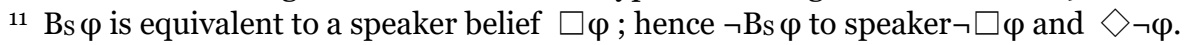

12 Defeasible entailment written as $>$ is based on Asher and Lascarides (2003). 


\section{Lukas Rieser: Quality of commitment}

When A observes S's assertion of $\varphi$ and assumes $S$ to be cooperative, i.e. that the conditions on felicitous assertion are satisfied, $\mathrm{B}_{\mathrm{A}} \mathrm{B}_{\mathrm{S}} \varphi$ follows from the inference rules in (11). When $S$ in turn assumes that A judged the assertion felicitous, $B_{S} B_{A} B_{S} \varphi$ follows. ${ }^{13}$ In this way, a public belief $\operatorname{PBS}_{S} \varphi$ arises from assertion of $\varphi$ by $S$ and assumed cooperativity, i.e. satisfaction of the belief and evidence conditions representing Gricean quality.

\subsection{Gricean Quality in interrogatives}

I propose that interrogatives come with a single preparatory condition $\neg B_{s} \varphi$, roughly corresponding to Searle's (1969) preparatory condition for questions that the speaker not know the answer.

\section{(14) Belief condition on $\operatorname{InTs}(\varphi): \neg \operatorname{Bs} \varphi$}

Note that this condition on $\operatorname{INTs}(\varphi)$ holds regardless of falling or rising intonation, i.e. it goes for both FIs and RIs (questions). An according Gricean-inspired maxim for interrogatives could go as follows.

Quality Int Do not doubt what you believe to be true.

In addition to this, the meaning of interrogative utterances is enriched by implicatures from forgoing their declarative alternatives. Choosing an interrogative over a declarative gives rise to what Geurts (2010) calls a Qimplicature, from the first Gricean maxim of quantity "Make your contribution as informative as required [...]" (Grice 1975). In the case of an FI, the Q-implicature is that the speaker does not entertain the belief that the forgone FD (assertion) makes public, thus $\operatorname{INTs}(\varphi) \downarrow$ gives rise to the implicature $\neg \operatorname{PBs} \varphi$, the negation of $\operatorname{PB} s \varphi$ from $\operatorname{DECs}(\varphi) \downarrow$, as shown below.

(15) Forgone commitment from $\operatorname{INTs}(\varphi) \downarrow: \neg \mathrm{PB} s \varphi$

(16) $\neg$ PBs $\varphi \leftrightarrow \mathrm{B}_{\mathrm{A}} \neg \mathrm{Bs} \varphi \wedge \mathrm{Bs}_{\mathrm{S}} \mathrm{B}_{\mathrm{A}} \neg \mathrm{Bs} \varphi$

In short, when commitment to $\varphi$ is forgone, an observer can assume that the speaker does not believe $\varphi$ to be true.

\subsection{Commitment in rising utterances}

Building on Gunlogson (2003) and its adaptation for Japanese particle utterances in Davis (2011), I assume final rising intonation in declaratives resolves a variable to the addressee, final falling intonation to the speaker.14 (17) and (18) show prosodically underspecified evidence and belief conditions on declaratives.

(17) Evidence condition on $\operatorname{DECs}(\varphi): \quad \operatorname{EV}_{s} B_{x} \varphi$

(18) Belief condition on $\operatorname{DECs}(\varphi)$ : $\quad$ Bs $\neg B_{x} \neg \varphi$

(where $\nearrow$ resolves $x$ to $A, \searrow$ resolves $x$ to $S$ )

13 The definition uses a simplified model with only two participants: S and A, and glosses over the fact that commitment by a manifest event gives rise to an in principle infinite number of higher order beliefs, $c f$. the definition of mutual introspection in Rieser (2017b).

14 Differing from Gunlogson and Davis, I assume the variable in the belief and evidence conditions rather than in commitments as [ ( $\left.\operatorname{EV}_{\mathrm{s}} \mathrm{B}_{\mathrm{x}} \varphi>\mathrm{Bs}_{\mathrm{x}} \varphi\right) \wedge \mathrm{EV}_{\mathrm{s}} \mathrm{B}_{\mathrm{x}} \varphi$ ] $\wedge \mathrm{B} s \neg \mathrm{B}_{\mathrm{x}} \neg \varphi \vdash \mathrm{Bs}_{\mathrm{x}} \varphi$, thus $\operatorname{PBs}_{\mathrm{x}} \varphi$ arises from $\operatorname{DECS}(\varphi)$. 
A final rise resolves the evidence and belief conditions as in (19) and (20) ${ }^{15}$.

(19) Evidence condition on $\operatorname{Decs}(\varphi) \lambda: \operatorname{EVs} B_{A} \varphi$

(20) Belief condition on $\operatorname{DECs}(\varphi) \gamma: \quad B s \neg B_{A} \neg \varphi$

Applying the inference rule as in (21) predicts $\mathrm{RD}$ commitment as in (22).

(21) $\left[\left(\mathrm{EV}_{S} \mathrm{~B}_{\mathrm{A}} \varphi>\mathrm{B}_{\mathrm{S}} \mathrm{B}_{\mathrm{A}} \varphi\right) \wedge \mathrm{EV}_{S} \mathrm{~B}_{\mathrm{A}} \varphi\right] \wedge \mathrm{B}_{\mathrm{S}} \neg \mathrm{B}_{\mathrm{A}} \neg \varphi \vdash \mathrm{BSB}_{\mathrm{B}} \mathrm{B}_{\mathrm{A}} \varphi$

(22) Commitment from $\operatorname{DECS}(\varphi) \lambda$ : $\quad \operatorname{PB}_{S} B_{A} \varphi$

The question of whether or not bare RDs exist in Japanese set aside ${ }^{16}$, commitment to a higher-order belief that the addressee beliefs the prejacent to be true is compatible with the observation that daroo-RDs convey speaker assumptions w.r.t. addressee belief, cf. section 5.3.

Turning to RIs (questions), I assume they have the standard interrogative preparatory condition shown in (23) that the speaker not believe the prejacent to be true. When the question is chosen over the declarative alternative (the RD), forgone commitment as in (24) arises.

(23) Belief condition on $\operatorname{InTs}(\varphi) \nearrow$ (Quality Int): $\neg \mathrm{Bs} \varphi$

(24) Forgone commitment from $\operatorname{INTs}(\varphi) \gamma: \quad \neg \operatorname{PBsB}_{A} \varphi$

Taken together, this accounts for the intuition that questions, while potentially conveying speaker bias towards or against the prejacent, are in principle neutral w.r.t. the addressee's beliefs, and are not felicitous when the speaker already knows (or believes to know) the answer.

\section{Daroo lowers the quality threshold}

I propose that daroo lowers the quality threshold, weakening the speaker commitment that arises from felicitous assertion. As commitment is defined in terms of public speaker belief, this requires a definition of weaker commitment in terms of weaker speaker belief $\mathrm{B}^{\text {daroo }} \mathrm{S} \varphi$ as defined in (26), shown along with the unmodified belief proposition in (25).

$$
\begin{aligned}
& \text { Bs } \varphi \text { is true iff DOXS } \subseteq \mathrm{W}^{\varphi} \\
& \mathrm{B}^{\text {daroo }} S \varphi \text { is true iff } \mid \text { DOXs } \cap W^{\varphi}|>| \text { DOXs } \cap W^{\natural \varphi} \mid \\
& \quad \text { (where } \mathrm{W}^{\urcorner \varphi} \text { denotes the set of worlds at which } \varphi \text { is false.) }
\end{aligned}
$$

(26) states that $\mathrm{B}^{\text {daroo }} \mathrm{S} \varphi$ holds iff there are more accessible worlds at which $\varphi$ is true than accessible worlds at which $\varphi$ is false. This means that the speaker considers $\varphi$ more likely than $\neg \varphi$, or that the subjective probability of $\varphi$ is more than $50 \%{ }^{17}$, which in turn has the consequence of a weaker evidence condition given the way that evidence and commitment are connected on the present proposal.

\footnotetext{
15 (20) is essentially the mirrored version of the belief condition on assertion requiring the speaker to not belief what is asserted to be false. A Grice-inspired maxim for RDs could thus be "do not commit the addressee to what you assume they believe to be false"

16 Polar RDs and Ris (questions) are not syntactically differentiated in Japanese.

17 For discussion of issues with the formal implementation of (gradable) likelihood see for instance Lassiter (2011). The likelihood that daroo encodes is, however, not gradable, thus porentially easier to capture.
} 


\subsection{The quality threshold and conjecture}

The lowered quality threshold directly accounts for weaker commitment from daroo-assertion, written as $\mathrm{PB}^{\text {daroo }} \mathrm{s} \varphi$, the weaker variant of $\mathrm{PB}_{\mathrm{s}} \varphi$.

(27) Commitment from $\operatorname{DECs}(\varphi$ daroo $) \searrow: \mathrm{PB}^{\text {daroo }} \mathrm{s} \varphi$

(28) $\mathrm{PB}^{\text {daroo }} \mathrm{S} \varphi \leftrightarrow \mathrm{B}_{\mathrm{A}} \mathrm{B}^{\text {daroo }} \mathrm{S} \varphi \wedge \mathrm{BSB}_{\mathrm{A}} \mathrm{B}^{\text {daroo }} \mathrm{S} \varphi$

$\mathrm{PB}^{\text {daroo }} \mathrm{S} \varphi$ is commitment from (daroo-)assertion and thus the result of addressee reasoning on manifest linguistic behavior. The evidence condition is also weakened to $\mathrm{EV}^{\text {daroo }} \mathrm{S} \varphi$, as "adequate evidence" (following Grice's formulation) for weaker commitment is lesser evidence than that required for full commitment.

(29) Evidence condition on $\operatorname{DECs}(\varphi$ daroo $) \backslash: \mathrm{EV}^{\text {daroo }} S \varphi$

(30) Belief condition on $\operatorname{DECs}(\varphi$ daroo $) \searrow$ : $\quad \neg \mathrm{BS} \neg \varphi$

The required strength of evidence thus depends on the respective speech act's quality threshold, represented as $\mathrm{EV}^{\mathcal{A}}$ and $\mathrm{B}^{\mathcal{A}}$ in the speech-act relative defeasible inference rules below, where $\mathcal{A}$ stands for a speech-act type, here bare utterances and such with daroo.

$$
\begin{aligned}
& \mathrm{EV}^{\mathcal{A}} \varphi>\mathrm{B}^{\mathcal{A}} \varphi \\
& {\left[\left(\mathrm{EV}^{\mathcal{A}} \varphi>\mathrm{B}^{\mathcal{A}} \varphi\right) \wedge \mathrm{EV}^{\text {daroo }} \mathrm{S} \varphi\right] \wedge \neg \mathrm{B} S \neg \varphi \vdash \mathrm{B}^{\text {daroo }} \mathrm{S} \varphi}
\end{aligned}
$$

Thus, $\mathrm{PB}^{\text {daroo }} \mathrm{S} \varphi$ arises from daroo assertions like (33) repeated from (1).

(33) Kanojo-wa moo kekkon-shita (no) daroo.` She-TOP already married-got no daroo

"She got married already, I bet".

The conveyed meaning of (33) without no is paraphrased in (34).

(34) S does not believe that she hasn't got married and has evidence supporting the assumption that she more likely got married than not, hence $\mathrm{S}$ commits to a belief that she more likely got married.

This is compatible with the guess reading of daroo-conjecture. As for no, I take it to add the following evidence condition ${ }^{18}$, where $\mathcal{X}$ represents all participants ( $\mathrm{A}$ and $\mathrm{S}$ in the simplified model).

(38) Evidence condition added by no: $\operatorname{EVx} \varphi$

(39) shows an according paraphrase of the no-daroo variant of (33).

(39) S does not believe that she hasn't got married and there is evidence available to all participants supporting the assumption that she more likely got married than not, hence $\mathrm{S}$ commits to a belief that she more likely got married.

18 See Rieser (2017b) for a more detailed analysis of the contribution of no, including utterances without daroo. Davis (2011) also proposes an analysis of no as an evidential marker based on the effect of no on the conveyed meaning of falling interrogatives. 
Clearly, in the scenario with evidence, it is preferable to add no, marking that the grounds for committing to the prejacent are publicly available evidence. The difference between the variant with and the that without no thus comes down to "guessing" based on evidence only available to the speaker, and making an inference based on publicly available evidence. The badness of the plain daroo-assertion in the evidence scenario is thus not encoded in the meaning of daroo, but arises from the availability of an alternative marking of such evidence with $\mathrm{no}^{19}$.

\subsection{The quality threshold in interrogatives}

The marked difference between the uses of FIs with and without daroo is in line with the conveyed meanings predicted by the present proposal. First, note that bare and daroo FIs do not differ in preparatory conditions, but only in forgone commitment arising as an implicature.

(40) Belief condition on $\operatorname{DECs}(\varphi$ daroo) $\downarrow$ : $\quad \neg \mathrm{Bs} \varphi$

(41) Forgone commitment from $\operatorname{INTs}(\varphi$ daroo $) \searrow$ : $\neg \mathrm{PB}^{\text {daroo }} \mathrm{S} \varphi$

The definition of $\neg \mathrm{PB}^{\text {daroo }} \mathrm{S} \varphi$ is given in (42) parallel to that of $\neg \mathrm{PBs} \varphi$ in (16).

(42) $\neg \mathrm{PB}^{\text {daroo }} \mathrm{S} \varphi \leftrightarrow \mathrm{B}_{\mathrm{A}} \neg \mathrm{B}^{\text {daroo }} \mathrm{S} \varphi \wedge \mathrm{B}_{\mathrm{S}} \mathrm{B}_{\mathrm{A}} \neg \mathrm{B}^{\text {daroo }} \mathrm{S} \varphi$

Next, the definition of negated belief under a lowered quality threshold is shown in (44) along with the non-negated version (43) repeated from (26).

(43) $\quad \mathrm{B}^{\text {daroo }} \mathrm{S} \varphi$ is true iff $\left|\operatorname{DOX}_{\mathrm{S}} \cap \mathrm{W}^{\varphi}\right|>\left|\operatorname{DOXS}_{\mathrm{S}} \cap \mathrm{W}^{\urcorner^{\varphi}}\right|$

(44) $\neg \mathrm{B}^{\text {daroo }} \mathrm{S} \varphi$ is true iff $\left|\operatorname{DOXS}_{s} \cap \mathrm{W}^{\varphi}\right| \leq\left|\operatorname{DOXS}_{\mathrm{S}} \cap \mathrm{W}^{\varphi}{ }^{\varphi}\right|$

There is a crucial difference between negated and non-negated daroobelief - the former allows the speaker to be neutral w.r.t. to the prejacent (i.e. the cardinality of accessible $\varphi$-worlds is the same as that of accessible $\neg \varphi$ worlds), while the latter excludes this case. Thus, negated daroo-belief means that the speaker is either neutral with regard to the prejacent, or biased against it, straightforwardly explaining the lack of speaker bias from daroo-FIs. Our example is repeated in (45) from (4).

(45) Kanojo-wa moo kekkon-shita(no) daroo ka $\{\triangleleft / \# \nearrow\}$ She-TOP already married-got no daroo INT

„I wonder if she (really) got married already."

The paraphrase of the daroo-FI without no goes as follows.

(46) $\mathrm{S}$ does not believe that she got married, and (even) forgoes to commit to a belief that she likely got married.

This accounts for the observation that daroo-FIs convey stronger doubt than plain ones, as indicated by insertion of "even" in the paraphrase: forgoing to fully commit to the prejacent $(\neg \mathrm{PBs} \varphi$ from the plain FI)

19 This is potentially a case of maximize presupposition, but can also be a Q-implicature from the plain version that there is no mutually accessible evidence, assuming that perceptual evidence activates the alternative with no. 


\section{Lukas Rieser: Quality of commitment}

constrains admissible doxastic states less than "even" forgoing to weakly commit to the prejacent $\left(\neg \mathrm{PB}^{\text {daroo }} \mathrm{S} \varphi\right.$ from the daroo-FI).

Consider next the paraphrase of the no-daroo-FI (45) given in (47).

(47) $\mathrm{S}$ does not believe that she got married, there is evidence available to all participants that she more likely got married, but $\mathrm{S}$ (even) forgoes to commit to a belief that she likely got married.

The addition of no brings out stronger doubt, making it plausible that previously held negative bias prevents $\varphi$ from (even weakly) committing to the prejacent, so that defeasible inference is blocked as in (48).

$$
\text { (48) }\left[\left(\mathrm{EV}^{\mathcal{A}} \varphi>\mathrm{B}^{\mathcal{A}} \varphi\right) \wedge \mathrm{EV}^{\text {daroo }} \mathrm{S} \varphi\right] \wedge \mathrm{B}^{\text {daroo }} \mathrm{S} \neg \varphi \nvdash \mathrm{B}^{\text {daroo }} S \varphi
$$

This is in line with the observation that no-daroo-FIs convey that publicly available evidence is not sufficient to change the polarity of speaker bias, and explains that a belief revision reading is only available in no-FIs without daroo lowering the quality threshold.

\subsection{The quality threshold in rising utterances}

I propose that in rising utterances, daroo has the same effect of lowering the quality threshold as in falling utterances. According evidence and belief conditions on daroo-RDs are as follows.

(49) Evidence condition on $\operatorname{Decs}(\varphi$ daroo $) \lambda: \quad \operatorname{EV}^{\text {daroo }} \mathrm{B} \mathrm{B}_{\mathrm{A}} \varphi$

(50) Belief condition on $\operatorname{DECs}\left(\varphi\right.$ daroo) $\lambda$ : $\quad B \quad B \neg B_{A} \neg \varphi$

This gives rise to weaker speaker commitment w.r.t. addressee belief.

(51) Commitment from $\operatorname{Decs}(\varphi$ daroo $) \lambda: \quad \mathrm{PB}^{\text {daroo }} \mathrm{S} \mathrm{B}_{\mathrm{A}} \varphi$

While in line with H\&D's analysis that daroo shifts the deictic center to the addressee ${ }^{20}$, my analysis differs in that daroo-RDs do not update addressee beliefs, but convey speaker assumptions w.r.t. addressee belief.

Also in line with $\mathrm{H} \& \mathrm{D}$, I take rising daroo-utterances to be RDs, pace Sudo (2013) who takes them to be polar questions with a question particle desho. Sudo observes that final rising desho-utterances "carry strong [...] epistemic bias, but no evidential bias", that is they are felicitous regardless of contextual evidence w.r.t the prejacent, and convey that the speaker is biased towards the prejacent. Both of these properties are atypical of Japanese polar questions which are generally sensitive to contextual evidence and give rise to epistemic bias of opposite polarity to that of the prejacent. Hence, the bias patterns of rising daroo-utterances suggest they are RDs. The relevant example is repeated as (52) from (6).

(52) Kanojo-wa kekkon-shiteiru desho(o). 7 She-TOP married-be daroo

"She's married, right?"

The meaning of (52) is predicted to be as paraphrased in (53).

20 With the caveat that I do not assume deictic shifting to only occur in daroo-utterances. 
(53) S does not believe that A believes she is still unmarried and has evidence that A more likely believes that she got married than not, hence commits to a belief that A more likely believes she got married.

This paraphrase accounts for the observation that daroo-RDs are used to confirm a speaker assumption about addressee belief, and corresponds to Moriyama's (1992) "inquiring” confirmations.

It remains to account for the marginal status of questions (RIs) with daroo. While H\&Ds suggestion that overt force marking blocks deictic shifting is a possible explanation, I suggest that there might be a more simple reason. Rising daroo-utterances are CG-maximizing as they, according to Sudo (2013) necessarily, convey the speaker is committed to the prejacent, and confirm whether the addressee is, too. Deriving an interrogative by adding $k a$, however, does not only give rise to forgone commitment, but also comes with the interrogative belief condition.

(54) Belief condition on INTs $\left(\varphi\right.$ daroo) $\lambda$ : $\quad \neg \mathrm{Bs}_{s}$

(55) Forgone commitment from INTs $\left(\varphi\right.$ daroo) $\lambda: \neg \mathrm{PB}^{\text {daroo }} \mathrm{S} \mathrm{B}_{\mathrm{A}} \varphi$

(54) obviously clashes with the prerequisite for a CG-maximizing reading that the speaker be committed to the prejacent, which explains the infelicity of daroo-questions as confirmations. When, on the other hand, the communicative intention is not CG-maximizing, Japanese offers a variety of polar questions to convey different constellations of epistemic and evidential bias while inquiring about the prejacent.

H\&D's observation that daroo-questions can be used in "quiz questions" (even though their example is of a $w h$-question and thus not directly comparable to the scope of data discussed here) can be explained as a marginal form of confirmation, where epistemic bias is to be avoided, in the quiz or exam case most likely in order not to reveal the correct answer, which the asker naturally knows.

\subsection{Accounting for confirmations}

Hara and Davis (2013) follow Groenendijk and Roelofsen (2009), assuming that assertive update excludes (pairs of) worlds from a context set. I suggest that this is not necessarily the case, but that only worlds at which the speaker does not believe the prejacent to be true are eliminated by addition of public beliefs to the context set ${ }^{21}$. Whether or not this leads to an update of the shared public beliefs of the participants, or CG update, depends on whether or not the addressee goes on to commit to the prejacent as well.

This is not to say, however, that there are no cases in which addition of a proposition to the common ground is a desired effect of assertion. I propose that confirming daroo-assertions are straightforwardly accounted for under the assumption that they (along with rising daroo-declaratives

${ }^{21}$ In Rieser (2017a), I propose a radically simplified view of context: a context is the same as a world; the world at utterance time being what utterances alter, in the case of assertions by adding (public) belief propositions. 


\section{Lukas Rieser: Quality of commitment}

discussed above) are conventionally CG-maximizing utterances. As such, they commit the speaker to a public belief that the prejacent is a shared belief, as shown in (56).

(56) Commitment from CG-maximizing assertion: $\mathrm{PBs}\left(\mathrm{Bs} \varphi \wedge \mathrm{B}_{\mathrm{A}} \varphi\right)$

When commitment is weakened by daroo's lowering of the quality threshold, the following preparatory conditions apply, where $\downarrow$ represents Moriyamas "abrupt final fall" to differentiate confirmations from the conjecture use of daroo-assertions. ${ }^{22}$

(57) Evidence condition on $\operatorname{DECs}(\varphi$ daroo $) \downarrow: \operatorname{EV}^{\text {daroo }} \mathrm{S}\left(\mathrm{BS} \varphi \wedge \mathrm{B}_{\mathrm{A}} \varphi\right)$

(58) belief condition on $\operatorname{DECS}(\varphi$ daroo $) \downarrow$ : $\quad \neg \operatorname{BS} \neg\left(\operatorname{Bs} \varphi \wedge B_{A} \varphi\right)$

The example of a falling daroo-confirmation is repeated in (59) from (6), with final intonation modified to $\downarrow$.

(59) Kanojo-wa kekkon-shiteiru daroo. $\downarrow$ She-TOP married-be daroo

"She's married, isn't she."

On the present analysis, the meaning of (59) can be paraphrased as in (60).

(60) $\mathrm{S}$ does not believe that it's not a shared belief that she's married and has evidence that it is likely a shared belief, hence commits to a belief that "she is married" is likely a shared belief.

If the speaker is already committed to the prejacent (which is particularly reasonable in the case of "pushing" confirmations in Moriyama's classification), weak speaker commitment to the prejacent being a shared belief entails weak speaker commitment to the prejacent being a belief of the addressee. Hence, (59) receives an interpretation parallel to that of daroo-RDs in terms of what is conveyed about the speaker's assumptions w.r.t. addressee belief.

The difference between rising and falling daroo-confirmations thus is that between "inquiring" and "pushing" variants: daroo-RDs make direct reference to addressee belief but not to shared belief, resulting in the inquiring confirmation reading. Confirming daroo-assertions, on the other hand, skip the addressee's confirmation, thus jumping to the conclusion, so to speak, that the prejacent is more likely a shared belief than not, giving rise to the pushing confirmation reading.

\section{Conclusion and outlook}

I have proposed an analysis of daroo as a speech act modifier lowering the quality threshold, thereby weakening speaker commitment so that lesser evidence is sufficient for felicitous assertion. I have shown that this unified

\footnotetext{
22 The existence of the specialized forms desho ${ }^{\top}$ and daro $\downarrow$ is circumstantial evidence for their marked status as conventionally CG-maximing utterances, but requires further investigation. I do not claim that daroo-assertions with a regular final fall can not be used as confirmations, but that the abrupt final fall disambiguates towards a (CG-maximizing) confirmation reading.
} 
semantics makes predictions on the conveyed meaning of darooutterances which are compatible with the observations in the literature. The analysis accounts not only for conjecture and doubt uses, but also for confirmation uses, which is an advantage over analyses on which daroo requires specific types of evidence, such as Hara and Davis (2013), and analyses assuming it marks specific types of inference, such as Takubo (2009), neither of which are obviously applicable to confirmations. Not considering the indirect evidential yooda to be an expression of the same class as daroo has the additional advantage of explaining why yooda has neither doubt- nor confirmation uses. Furthermore, the framework for speech act felicity used for the analysis is independently motivated as it is based on widely accepted Gricean conversational maxims and compositionally accounts for differences in the felicity conditions of four utterance types differentiated by force and prosody.

Regarding possible expansion of the analysis beyond daroo, it is necessary to account for other expressions of (subjective) probability or likelihood, such as epistemic modals and modal adverbs, and for evidential expressions needs, on either the propositional or on the speech-act level of utterance meaning in the proposed framework. Expanding the scope of the analysis to Japanese sentence-final expressions which make reference to speaker and addressee belief is a particularly interesting perspective. For instance, there is functional overlap of daroo in confirmation use and Japanese sentence-final expressions such as outer negation in falling polar interrogatives (dewanai-ka, also occurring in contracted forms like janai$k a$ and jan) as well as sentence-final particles (concretely the particle combination yo-ne), suggesting these expressions as suitable starting points for further research.

In order to test the cross-linguistic validity of the framework in general and the proposed analysis in particular, application to languages other than Japanese is a promising perspective. There are, for instance, interesting parallels between the functions of daroo and that of the German particle wohl, as already mentioned by Hara (2006), who applies tests Zimmermann (2004) proposes for determining the scope of German wohl to daroo. While wohl in isolation closely resembles daroo in conjecture and doubt uses, the particle combination doch wohl has a confirmation use similar to the "pushing" variety of daroo-confirmations, as discussed in Rieser (2013).

Finally, what strategies languages without a comparably rich inventory of speech-act level operators, such as English, employ to realize the communicative functions that daroo-utterances cover in Japanese is an intriguing question for further research complementing the expansion of the analysis to languages that have similar expressions 


\section{Lukas Rieser: Quality of commitment}

\section{References}

Asher, N. and Lascarides, A. 2003. Logics of conversation. Cambridge University Press.

Austin, J. 1962. How to do things with words. Clarendon Press.

Büring, D. and Gunlogson C. 2000. Aren't Positive and Negative Polar Questions the Same? Ms., UCLA/UCSC.

Davis, C., Potts, C. and Speas, M. 2007. The pragmatic values of evidential sentences. In: Proceedings of Semantics and Linguistic Theory 17, pp. 71-88.

Davis, C. 2011. Constraining Interpretation: Sentence Final Particles in Japanese. PhD thesis, University of Massachusets - Amherst.

Geurts, B. 2010. Quantity implicatures. Cambridge University Press.

Grice, H.P. 1975. Logic and conversation. In: Cole, P. and Morgan, J. (Eds.) Syntax and Semantics Vol. 3: Speech Acts, pp. 41-58. Academic Press.

Groenendijk, J. and Roelofsen, F. 2009. Inquisitive semantics and pragmatics. In: Proceedings of SPR 9, ILCI international workshop on semantics, pragmatics, and rhetoric, pp. 41-72.

Gunlogson, C. 2003. True to form: Rising and falling declaratives as questions in English. PhD thesis, UCSC.

Hara, Y. 2006. Grammar of Knowledge Representation: Japanese Discourse Items at Interfaces. $\mathrm{PhD}$ thesis, University of Delaware.

Hara, Y. and Davis, C. 2013. Darou as a deictic context shifter. In: Proceedings of Formal Approaches to Japanese Linguistics 6, pp. 41-56.

Lassiter, D. 2011. Measurement and Modality: The Scalar Basis of Modal Semantics. PhD thesis, NYU.

Minami, F. 1974. Gendai nihongo no koozoo. Taishukan Publishing. [The structure of modern Japanese.]o

Morimoto, J. 1994. Hanashite no shukan o arawasu fukushi ni tsuite. Kuroshio. [On adverbs that express the speaker's subjective view.]

Moriyama, T. 1992. Nihongo ni okeru 'suiryoo' o megutte. Gengo Kenkyu 101, pp. 64-83. [Around 'inference' in Japanese.]

Rieser, L. 2013. Function and Meaning of German Modal Particles by their Japanese Correspondents. MA thesis, Universität Wien.

Rieser, L. 2017a. Belief States and Evidence in Speech Acts: The Japanese Sentence Final Particle no. PhD thesis, Kyoto University.

Rieser, L. 2017b. Discourse particles as CCP-modifiers: German doch and ja as context filters. In: Otake, M., Kurahashi, S., Ota, Y., Satoh, K., Bekki, D. (Eds.) New Frontiers in Artificial Intelligence (=Proceedings of LENLS 13), pp. 93108. Springer.

Searle, J. R. 1969. Speech Acts. Cambridge University Press.

Stalnaker, R. C. 2002. Common ground. Linguistics and Philosophy, 25, pp. 701721.

Sudo, Y. 2013. Biased Polar Questions in English and Japanese. In: Gutzmann, D. and Gärtner, H.-M. (Eds.) Beyond Expressives: Explorations in UseConditional Meaning, Leiden, Brill, pp. 275-296.

Takubo, Y. 2009. Conditional Modality: Two Types of Modal Auxiliaries in Japanese. In: Pizziconi, B. and Kizu, M. (Eds.) Japanese Modality: Exploring its Scope and Interpretation. Basingstoke: Palgrave Macmillan, pp. 150-182.

Zimmermann, M. 2004. Discourse particles in the left periphery. ZAS Papers in Linguistics 35.2, pp. 543-566. 